Revista Eletrônica de Ciência Administrativa (RECADM) - ISSN 1677-7387

Faculdade Cenecista de Campo Largo - Coordenação do Curso de Administração 3 v. 2, n. 2, nov./2003 - http://revistas.facecla.com.br/index.php/recadm/

\title{
E-MARKETING : UMA ANÁLISE DOS DIFERENCIAIS NECESSÁRIOS PARA ATUAR NO COMÉRCIO ELETRÔNICO - ESTUDO DE CASO
}

PUCINELLI, Evelyn Aparecida (evelynelli@ig.com.br) - Acadêmica do Curso de Graduação em Comércio Exterior - UNIMEP.

GIULIANI, Antonio Carlos (giuliani.marketing@uol.com.br) - Professor e Coordenador de Mestrado Profissional Stricto Sensu em Administração - UNIMEP.

\section{RESUMO}

Com a evolução do comércio eletrônico no Brasil, foi necessário uma reorientação por parte das empresas que por muitos anos estavam acostumadas com um tipo de comércio do comercial para efetuar a compra de um produto. No entanto, este tipo de transação comercial continua predominando num país que ainda possui diversas classes sociais, da qual a cultura de informação, a tecnologia ainda são precárias em relação aos países mais desenvolvidos. A prática de comércio on line no Brasil está em pleno crescimento, induzindo muitas empresas a operarem num novo tipo de mercado denominado loja virtual ou melhor dizendo, o mercado business to consumer, (B2C). Diante desse cenário, o estudo abordou as vantagens e desvantagens desta prática de comércio, apontando os principais aspectos que podem gerar problemas para as empresas operantes do mercado B2C. analisou-se a evolução do comércio eletrônico no Brasil e no mundo; a postura do consumidor brasileiro, identificando os fatores que ameaçam o e-commerce. Conclui-se com as reflexões os mecanismos necessários para driblar com esse novo tipo de implantação de um site eletrônico, através da análise de dois estudos de casos, as empresas Redemarket e Submarino, sendo apontado os aspectos importantes que são necessário para um bom funcionamento do e-marketing no mercado $\mathrm{B} 2 \mathrm{C}$.

Palavras chaves: marketing digital, comércio eletrônico, business to consumer.

\section{ENTENDENDO O E-COMMERCE}

Com o objetivo de se tornar a nova tendência mercadológica dos próximos anos, o e-commerce ${ }^{1}$, segundo Bretzke ${ }^{2}$, é o fenômeno que modificará a forma de comercialização de serviços e produtos, consistindo em ser uma vitrine eletrônica da qual apresentam-se mercadorias por meio de catálogos, descrições de produtos, listas de preços e outras informações de onde os clientes podem vizualizar uma loja e fazer seu pedido.

O processo de difusão do comércio eletrônico está intimamente ligado ao surgimento da Amazon.com em 1995, nos EUA. Devido ao sucesso das vendas da Amazon.com, inúmeras empresas de todo o mundo se interessaram pelo novo conceito de varejo on line e como conseqüência direta destas iniciativas, houve um rápido crescimento desta forma de comércio na maior parte dos países industrializados do mundo. Os EUA, que são hoje responsáveis por cerca de $70 \%$ do volume total de transações on line, em todo o mundo, são um bom exemplo do ritmo atual e previsto de crescimento do comércio eletrônico. No Brasil, calcula-se que 10 milhões de brasileiros já estejam conectados á Internet no Brasil. Desses, apenas 300 mil acessam a rede por meio de banda larga, que é um sistema mais veloz que o das linhas telefônicas convencionais ${ }^{3}$.

\footnotetext{
${ }^{1}$ Comércio eletrônico.

${ }^{2}$ BRETZKE.Miriam. Marketing de relacionamento e competitividade em tempo real.2000. p.72-75

${ }^{3}$ NICOLETTA, Constabille. Publicação eletrônica em E-bit: Brasileiros abrem o bolso na rede. Bit noticias, fev. 2002. Disponível em:
} 
Revista Eletrônica de Ciência Administrativa (RECADM) - ISSN 1677-7387

Faculdade Cenecista de Campo Largo - Coordenação do Curso de Administração 4 v. 2, n. 2, nov./2003 - http://revistas.facecla.com.br/index.php/recadm/

\subsection{Os prós e os contras do comércio eletrônico}

O comércio eletrônico apresenta vários fatores que implicam em vantagens e desvantagens para as empresas operarem neste mercado. Entre as principais vantagens apresentadas e analisadas pelos autores Novaes ${ }^{4}, \mathrm{Kotler}^{5}$ e Bretzke $^{6}$ encontram-se: exposição dos produtos e serviços, tanto em nível nacional como mundial; maior agilidade entre consumidores e vendedores; redução da burocracia; fácil acesso a qualquer tipo de informação; maior comodidade e conveniência para o consumidor e eliminação de barreiras físicas, culturais através de novos canais de distribuição.

Os aspectos que podem ser considerados desvantagens do comércio eletrônico são: fraude, da qual o consumidor convive com o receio de que seus dados sejam violados; facilidade de copiar ilegalmente marcas, produtos ou serviços devido a facilidade de informação; reação adversa de consumidores, permitindo ao cliente expressar sua insatisfação sobre o produto; navegação frustrante e estrutura operacional, pois se uma empresa não estiver bem estruturada operacionalmente, dificilmente a empresa poderá garantir a entrega da mercadoria certa no prazo combinado.

\subsection{Problemáticas}

Entre os principais problemas enfrentados pelas empresas operadoras de ecommerce estão relacionadas com aspectos que envolvem : cliente, propaganda, concorrência e logística. Dentre as questões relacionadas á estes aspectos, devem ser mencionadas algumas questões importantes :

Quais as dificuldades para o consumidor efetuar uma comprar via web ?

Quais fatores que podem garantir fidelização do cliente em relação ás compras via e-commerce?

Quais fatores diferenciais que estas empresas poderão adquirir para assegurar boa imagem no mercado?

Quais estratégias publicitárias que as lojas virtuais podem adotar para atrair o consumidor?

Qual a relação de concorrência entre as empresas operantes do mercado B2C com as empresas operantes do mercado tradicional ?

Qual postura de mercado que uma loja virtual deverá adquirir diante das lojas concorrentes?

Quais dificuldades encontradas pelas empresas que operam no comércio eletrônico em garantir uma boa operação logística?

As empresas de e-commerce encontram dificuldades em trabalhar com serviços terceirizados?

\section{ANALISANDO O MERCADO BUSINESS TO CONSUMER}

Esta é uma prática de comércio mais difundida, no qual consiste em ser uma categoria em que a empresa vende diretamente ao consumidor. É a modalidade que engloba os sites que visam comercializar produtos e serviços aos consumidores

<http://www.e-bit.com.br/ebit1/bitnoticias/htm/02fevereiro25_meiomensagem.htm>. Acesso em: 23/Ago/2002

${ }^{4}$ NOVAES.Antonio Galvão. Logística e gerenciamento da cadeia de distribuição. p. 76

${ }^{5}$ KOTLER. Philip. Administração de Marketing. 2000. p. 72

${ }^{6}$ BRETZKE.Miriam. Marketing de relacionamento e competividade em tempo real. p.72-75 
Revista Eletrônica de Ciência Administrativa (RECADM) - ISSN 1677-7387

Faculdade Cenecista de Campo Largo - Coordenação do Curso de Administração 5 v. 2, n. 2, nov./2003 - http://revistas.facecla.com.br/index.php/recadm/

finais. O consumidor entra no site da empresa em busca de um produto, informações referentes ao mesmo, tais como manual técnico, funcionamento, preço e prazo de entrega. Satisfeito com as informações ele começa a realizar a compra, escolhendo a forma de pagamento do produto. Este tipo de comércio permite manter baixos estoques de produto que podem ser montados ou adquiridos na medida em que são escoados. Utiliza o sistema make to order que consiste em produzir apenas quando existe um pedido colocado. Visa aumentar o grau de integração entre as empresas e consumidores, permitindo maior flexibilidade, além de maior competitividade. ${ }^{7}$

Este tipo de modalidade está relativamente retraído no Brasil, principalmente quando se compara com o movimento nos EUA. Mas isto explica-se pelo fato de que nos EUA a população têm mais acesso a computadores e está mais habituada a usar internet. Outro fator importante são os custos das chamadas telefônicas locais que nos Estados Unidos é muito mais baixa tanto em relação ao Brasil quanto aos demais países do mundo.

\subsection{Diagnóstico dos fatores ameaçadores do e-commerce}

\subsubsection{Cliente}

É preciso que as empresas deixem de focar em novos clientes e passem a se preocupar mais em reter os já existentes. Segundo $B$ rondmo ${ }^{8}$, os métodos que deverão ser adotados para este fim, consiste no engajamento dos clientes em um diálogo com a empresa e por intermédio da construção de relacionamentos duradouros e orientados para serviços.

A comunicação feita na internet, de acordo com Karsaklian ${ }^{9}$ possui objetivos básicos como por exemplo, atrair a atenção do internauta, identificá-lo e fidelizá-lo. Ele acredita que, o consumidor do e-commerce é mais exigente, principalmente pela facilidade de informação, pelo privilégio de comparar preços simultaneamente, pela qualidade do atendimento das lojas, o que o torna mais seletivo em sua escolha pelo produto e pela loja virtual.

\subsubsection{Propaganda}

Referindo-se a propaganda e marketing feitos no mercado virtual atualmente, pode-se concluir que as empresas que operam com e-commerce possuem na sua grande maioria, sites muito parecidos. Para Modahl ${ }^{10}$, a impressão do cliente em relação á empresa muitas vezes é determinada através do desempenho dos servidores, o layout ${ }^{11}$ do site, o design ${ }^{12}$ das páginas e o funcionamento do sistema de e-mail ${ }^{13}$. Ele afirma que existem três caminhos que poderão criar valor á empresa que opera ou deseja operar neste mercado, que são: A loja poderá desenvolver a

\footnotetext{
${ }^{7}$ PUBLIFOLHA. Manual Prático da Internet. 2002. p. 121-122

${ }^{8}$ BRONDMO. Hans Peter. Fidelização. 2001. p. 19

${ }^{9}$ KARSAKLIAN. Eliane. Cybermarketing. Op. cit. p.75-76

${ }^{10}$ MODAHL. Mary. Agora ou Nunca: como ganhar a guerra pelos consumidores na Internet. 2000. p. 40-41

${ }_{11}^{11}$ Diagramação do site

12 Estilo visual do site

${ }^{13}$ Abreviatura de Eletronic Mail, em português: Correio Eletrônico.

${ }^{14}$ KARSAKLIAN. Eliane. Op. cit. p. 33-40

15 Banco de dados
} 
Revista Eletrônica de Ciência Administrativa (RECADM) - ISSN 1677-7387

Faculdade Cenecista de Campo Largo - Coordenação do Curso de Administração 6 v. 2, n. 2, nov./2003 - http://revistas.facecla.com.br/index.php/recadm/

marca com base nas experiências dos consumidores; saber controlar a distribuição física; e saber usar as informações sobre o consumidor.

Para que se obtenha uma completa estratégia de mercado, é necessário, segundo as observações de Karsaklian ${ }^{14}$, haver além dos 4 P's (preço, produto, praça e promocional), os 2 D's, que são o Diálogo e o Data base ${ }^{15}$. Pois no comércio eletrônico precisa haver diálogo para se interagir via web e para isto é necessário que exista um banco de dados, nos quais são armazenados vários tipos de informações dos internautas.

\subsubsection{Concorrência}

Quanto a competividade via internet, de acordo com Modahl ${ }^{16}$, as empresas pioneiras desafiam práticas comerciais em diversas indústrias de consumo e isto causa sérias desvantagens para as empresas tradicionais. Dentre as medidas tomadas pelas empresas pioneiras para ganhar em competitividade estão: os novos modelos de preços, do qual as lojas virtuais apostam pela baixa dos preços e obter lucro no volume de vendas; expectativas de melhorias no serviço ao consumidor, que possui a vantagem dos negócios via internet estarem abertos durante 24 horas por dia, o que permiteo aos consumidores buscarem informações sobre os produtos antes de comprá-los e os novos meios para distribuição dos produtos, tendo como diferencial a entrega em domicílio.

\subsubsection{Logística}

Dentro das análises de Novaes $^{17}$, as empresas vêm buscando uma boa operação logística como diferencial para as vendas via web. Para ele, a logística precisa ter um preparo no que diz respeito ás condições de armazenagem dos diferentes produtos para estocagem até á entrega feita no prazo correto e em qualidade ao consumidor final. Seguindo as análises de Karsaklian ${ }^{18}$, a rapidez, a qualidade e a reatividade das empresas são os fatores principais de competitividade no mercado eletrônico para garantir um bom desempenho logístico. Quanto á um prestador de serviços logísticos, é necessário que a empresa terceirizada conheça as características dos diferentes tipos de produtos; zona de distribuição; prazos estabelecidos pela loja ao consumidor, variação de quantidade de encomendas por ano e por zona que a empresa precisa estar preparada; média de gastos dos clientes por pedido, quantidade e valor total e serviços que a empresa pretende oferecer em matéria de transporte.

\subsubsection{Preço}

Segundo as afirmações de $\operatorname{Karsaklian}^{19}$, as empresas continuam calculando os preços de seus produtos baseadas em três critérios principais que são: custos de produção e de comercialização; concorrência e demanda. Existem além disso, quatro fatores que contribuem para a alta de preços na net que são: altos custos de logística e de distribuição; comissões pagas aos sites de busca, os leilões

\footnotetext{
${ }^{16}$ MODAHL. Mary. Op. cit. 2000. p. 98

${ }^{17}$ NOVAES. Antonio Galvão. Op. cit. p. 55,84

${ }^{18}$ KARSAKLIAN. Eliane. Op. cit. p. 84-91

${ }^{19}$ KARSAKLIAN. Eliane. Op. cit. p. 46-47
} 
Revista Eletrônica de Ciência Administrativa (RECADM) - ISSN 1677-7387

Faculdade Cenecista de Campo Largo - Coordenação do Curso de Administração 7 v. 2, n. 2, nov./2003 - http://revistas.facecla.com.br/index.php/recadm/

concorridos que podem elevar os preços dos produtos e os investimentos em propaganda são mais importantes do que no mercado real.

\subsubsection{Produto}

No que diz respeito aos produtos disponibilizados pela internet, Karsaklian ${ }^{20}$ afirma que o comércio eletrônico se divide pelos produtos que precisam de canais de distribuição e produtos que existem em função da net, como por exemplo, os sites de busca.

\subsubsection{Diálogo}

Em relação ao diálogo que deve ser praticado nas empresas, Karsaklian ${ }^{21}$ ressalta que o principal objetivo de fazer com que o internauta se comunique simultaneamente com a empresa é propor um diálogo mais fácil e simples com os clientes, favorecendo uma relação mais próxima e procurando fidelizá-los, além de possibilitar a conquista de clientes potenciais.

\subsubsection{Data Base}

Karsaklian ${ }^{22}$ acredita que o cliente contribui fortemente na constituição do bancos de dados de uma empresa, uma vez que são respondidos questionários virtuais, respostas a mala diretas, e-mails, visita ao web site da empresa, entre outros.

\section{METODOLOGIA DE ESTUDO}

O estudo procurou trabalhar com pesquisa exploratória através de análise de dados coletados entre duas empresas que obtiveram certificação ouro e diamante na avaliação geral pela e-bit, empresa que realiza pesquisas sobre tendências e hábitos de e-commerce no Brasil, o que as demais empresas conveniadas à este site, premiadas com prata e bronze na avaliação geral, deverão fazer para alcançarem o mesmo nível de qualidade das duas empresas que serão analisadas neste estudo.

Foram utilizadas informações contidas no site da e-bit, para desenvolvimento da análise, duas empresas que atuam no mercado B2C: a Submarino, loja de departamentos que atua com vendas de Cd's e livros principalmente, e a Redemarket, shopping virtual. Ambas encontram-se entre as 20 maiores empresas de e-commerce no Brasil.

O estudo apresentou estratégias destas duas empresas baseadas no composto 4P's e 2D's. Será demonstrado através de pesquisas de várias fontes, o que estas duas empresas fizeram e continuam fazendo para estarem num ótimo posicionamento no mercado B2C. A avaliação geral se deu através de um questionário disponível pela e-bit aos consumidores que efetuaram compras nestas empresas para que eles pudessem avaliar os seguintes quesitos :

ß Preço;

ß Seleção dos produtos e informação sobre os produtos;

B Facilidade ao comprar;

B Manuseio e envio dos produtos; entrega no prazo e qualidade dos produtos;

B Atendimento ao cliente;

\footnotetext{
${ }^{20}$ Ibid. Op. cit. p. $40-43$

${ }^{21}$ KARSAKLIAN. Eliane. Op. cit. p. 67-70

${ }^{22}$ Ibid. Op. cit. p. 70
} 
Revista Eletrônica de Ciência Administrativa (RECADM) - ISSN 1677-7387

Faculdade Cenecista de Campo Largo - Coordenação do Curso de Administração 8 v. 2, n. 2, nov./2003 - http://revistas.facecla.com.br/index.php/recadm/

B Navegação;

B Política de privacidade

A partir dos quesitos avaliados, as empresas recebem certificação da e-bit por medalhas bronze, prata, ouro ou diamante, dependendo da performance de cada quesito. O Submarino, através de 170.528 avaliações que recebeu de seus clientes, obteve certificação diamante, enquanto que a Redemarket recebeu 2.455 avaliações de seus clientes, sendo certificada com medalha ouro. $O$ total de avaliações feitas foram considerados para setembro de 2002.

\section{ANALISANDO E INTERPRETANDO OS DADOS DAS EMPRESAS.COM}

As empresas Submarino e Redemarket foram analisadas de acordo com um programa de avaliação de lojas de comércio on line da e-bit ${ }^{23}$. As lojas são classificadas a partir de dez ítens, através da opinião de consumidores das empresas que serão analisadas neste estudo. Após a realização das compras, o consumidor responde a uma rápida pesquisa, clicando no banner bitRate ao fim de cada compra em todas as lojas conveniadas á e-bit. Alguns dias depois, a e-bit entrará em contato com o consumidor, para que através de outra pesquisa, a e-bit possa se certificar se o produto chegou no prazo previsto, em boas condições e se foi realmente o que o cliente comprou. Com esta avaliação, a e-bit têm a possibilidade de converter as notas dadas pelos consumidores, em medalhas diamante, ouro, prata e bronze e atribuí-las a cada loja, identificando assim os melhores lugares para comprar na web.

A Submarino, surgiu em 1999, quando a livraria virtual Booknet foi comprada por um grupo de empreendedores. Hoje é um dos maiores sites de comércio eletrônico no Brasil, sendo premiado diversas vezes, liderando rankings dos sites Opinia e e-bit e sendo líder de audiência desde setembro de 2000, segundo agência Média Matrix. ${ }^{24}$

A Redemarket iniciou suas atividades em 1998, em Curitiba, Paraná. Atualmente ela ocupa a $14^{\circ}$ posição no ranking das melhores lojas virtuais do Brasil, estando ao lado de grandes nomes do comércio eletrônico, como Americanas, Submarino e Ponto Frio. ${ }^{25}$

\subsection{Preço}

Através da análise obtida pela e-bit foi constatado que ambas empresas obtiveram premiação prata, o que significa que os preços praticados por elas não são os melhores mas também não são tão caros. Conforme pesquisa feita no site Opinia ${ }^{26}$, das 7 empresas pesquisadas, a Submarino encontrou-se em $1^{\circ}$ lugar na categoria de preço de Cd's, enquanto que em relação à preço de livros, obteve o $6^{\circ}$

\footnotetext{
${ }^{23}$ E-bit.com.br. Publicação eletrônica. Disponível em: <http://www.ebit.com.br>. Acesso em: 22 ago. 2002

24 FERNANDA, C. Publicação eletrônica [mensagem pessoal]. Mensagem recebida por <eapucinelli@columbia.com.br> em 23 ago. 2002

${ }^{25}$ Rede Market nos jornais: Compra pela internet conquista mais espaço. O Estado do Paraná, Paraná, 24 abr. 2001. Disponível em:

<http://www.redemarket.com.br/imprensa/impressa/estado.htm>. Acesso em 22 set. 2002
}

${ }^{26}$ Opinia.com.br. Publicação eletrônica. Disponível em: <http://www.opinia.com.br>. Acesso em: 04 out. 2002 
Revista Eletrônica de Ciência Administrativa (RECADM) - ISSN 1677-7387

Faculdade Cenecista de Campo Largo - Coordenação do Curso de Administração 9 v. 2, n. 2, nov./2003 - http://revistas.facecla.com.br/index.php/recadm/

lugar no ranking. Para a Redemarket, a pesquisa foi analisada no site da e-bit ${ }^{27}$, da qual a empresa ocupava o $3^{\circ}$ lugar num ranking de 13 empresas do segmento de flores. No que diz respeito a preço de presentes, a Redemarket encontra-se em $2^{\circ}$ lugar numa escala de 12 empresas premiadas pelos seus consumidores ${ }^{28}$.

\subsection{Produto}

As duas empresas obtiveram premiação ouro no quesito seleção e informação sobre os produtos. Quanto á seleção dos produtos de acordo com a ebit $^{29}$, significa que a loja possui grande variedade de produtos e de boa qualidade. No quesito informação, quer dizer que é possível fazer comparações de preço, qualidade com outros produtos semelhantes no próprio site da loja. O Submarino dispõe de 12 categorias de produtos que subdividem-se de forma detalhada para 0 cliente escolher e vizualizar ampla informação. No caso da Redemarket, são disponibilizadas diversar categorias, com produtos diferenciados, apresentando informações detalhadas dos produtos.

\subsection{Promocional}

A facilidade ao comprar insere no contexto promocional, da qual através de da certificação ouro concedida pela e-bit para as duas empresas, constatou-se que a Submarino e a Redemarket possuem telas de fácil acesso, da qual o cliente não precisa acessar diversas páginas para concluir uma compra.

\subsection{Logistica}

Os quesitos avaliados neste aspecto foram: manuseio e envio dos produtos, entrega no prazo e qualidade dos produtos, da qual ambas empresas obtiveram ouro na premiação da e-bit.

Em relação ao Submarino, o produto é localizado através de um sistema eficiente cuja conferência dos pedidos é feita durante o dia. Quanto á entrega , o Submarino disponibiliza do serviço "Submarino Atômico", que agiliza a entrega e garante a qualidade do produto entregue ao cliente. ${ }^{30}$

Para a Redemarket, a empresa conta com um prestador de serviços logísticos que garante a entrega do produto ao cliente em perfeito estado de conservação, afirma Freder ${ }^{31}$.

27 E-bit.com.br. Publicação eletrônica. Sub_categoria Flores. Lojas classificadas por preços. Disponível em: <http://www.ebit.com.br/ebit1/rate/asp/modelo_rate_lojas_o.asp>. Acesso em: 05 out. 2002

${ }_{28}$ Idem. Publicação eletrônica.Sub_categoria Presentes diferentes.Lojas classificadas por preços. Disponível em:<http://www.e-bit.com.br/ebit1/rate/asp/modelo_rate_lojas_o.asp>.Acesso em 05 out. 2002

${ }^{29}$ E-bit.com.br. Publicação eletrônica. Pontuação_Seleção. Disponível em:

<http://www.e-it.com.br/ebit1/Rate/html/info_pontuacao2_o.htm>. Acesso em 22 ago. 2002

${ }^{30}$ Submarino.com.br. Publicação eletrônica. Seção Auto-Atendimento. set. 2002. Disponível em: <http://www/submarino.com.br/local/autoajuda/home_autoajuda_entrega_exterior.asp>. Acesso em: 24 set. 2002

${ }^{31}$ FREDER, M. Publicação eletrônica [mensagem pessoal]. Mensagem recebida por <eapucinelli@columbia.com.br>. Em 27 set. 2002

32 Todos os caminhos levam ao Submarino. O atendimento do portal. Consumidor Moderno, jul. 2001. Disponível em: <http://www.padraoeditorial.localweb.com.br/c/pages/materia.asp?id=59>. Acesso em: 22 set. 2002

${ }^{33}$ Redemarket.com.br. Atendimento ao cliente. Disponível em:

<http://www.redemarket.com.br/atendimento_online/atend_online.gif>. Acesso em 26 out. 2002 
Revista Eletrônica de Ciência Administrativa (RECADM) - ISSN 1677-7387

Faculdade Cenecista de Campo Largo - Coordenação do Curso de Administração 10

v. 2, n. 2, nov./2003 - http://revistas.facecla.com.br/index.php/recadm/

\subsection{Diálogo}

No quesito qualidade no atendimento, ambas empresas obtiveram premiação ouro, o que significa que muitas vezes o cliente não precisa se comunicar com a loja, conseguindo visualizar o status do pedido e da entrega on line.

O Submarino disponibiliza do serviço SAC, atendimento on line e televendas. A empresa possui uma ferramenta de atualização que é feita todos os dias, facilitando a comunicação com o consumidor ${ }^{32}$. Marcos Freder $^{33}$ da Redemarket acredita que a empresa precisa manter um relacionamento o mais pessoal possível para que o cliente sinta-se à vontade em ligar, dar sugestões, tirar dúvidas e até fazer reclamações, podendo ser feito pelo serviço SAC ou pelo serviço de e-mail.

\subsection{Data Base}

Para Murilo Tavares ${ }^{34}$, presidente do Submarino, o banco de dados deve registrar todos os contatos que são feitos por e-mails ou por fone. Em relação ao chat, a empresa está reformulando o banco de dados a fim registrado todos os diálogos feitos on line com o consumidor. A Redemarket possui um serviço chamado "Cliente Vip", da qual arquiva o cadastro do cliente a partir da primeira compra, possibilitando a visualização do seu histórico de pedidos ${ }^{35}$.

\subsection{Navegação das lojas}

Quanto a navegação de ambas as lojas, a e-bit ${ }^{36}$ premiou com ouro, o que pode significar que o site é mais rápido do que os demais do seu segmento, é fácil a localização dos produtos da loja e de boa navegação. As duas lojas possuem fácil acesso aos departamentos, aos produtos, o que torna mais simples a realização da compra.

\subsection{Política de privacidade}

A política de privacidade nas duas lojas virtuais foram premiadas com ouro. Isso quer dizer que o consumidor se sentiu protegido com a política da loja. Tanto a Submarino quanto a Redemarket possuem sistema de proteção, capaz de codificar as informações e arquivá-las num ambiente de acesso exclusivo da loja, não permitindo a violação das informações por terceiros ${ }^{37}$.

\section{CONCLUSÃO}

A dificuldade de navegar numa loja de e-commerce, torna o consumidor desmotivado em efetuar uma compra, o que causa uma imagem negativa da loja no mercado. A ausência de uma boa política de privacidade no site pode gerar desistência da compra pelo internauta, pois é necessário que o cliente sinta-se protegido em informar seus dados pessoais ao banco de dados da empresa.

\footnotetext{
34 Todos os caminhos levam ao Submarino. O relacionamento com o cliente. Consumidor Moderno, jul. 2001. Disponível em: <http://www.padraoeditorial.localweb.com.br/c/pages/materia.asp?id=59> Acesso em: 22 set. 2002

${ }^{35}$ FREDER. M. Informação verbal em 24 out. 2002

${ }^{36}$ E-bit.com.br. Publicação eletrônica. Pontuação_Navegação. Disponível em:

<http://www.e-it.com.br/ebit1/Rate/html/info_pontuacao5_o.htm>. Acesso em 22 ago. 2002

${ }^{37}$ E-bit.com.Br. Publicação eletrônica. Pontuação_Privāidade. Disponível em:

<http://www.e-bit.com.br/ebit1/Rate/html/info_pontuacao9_o.htm>. Acesso em 22 ago. 2002
} 
Revista Eletrônica de Ciência Administrativa (RECADM) - ISSN 1677-7387

Faculdade Cenecista de Campo Largo - Coordenação do Curso de Administração ${ }_{11}$ v. 2, n. 2, nov./2003 - http://revistas.facecla.com.br/index.php/recadm/

Os fatores que as empresas de e-commerce podem adotar como diferencial para fidelizar o cliente são a entrega no prazo, o diálogo e o preço. Enquanto a Submarino aposta no Submarino Atômico, que garante entrega rápida e segura, a Redemarket acredita num relacionamento o mais pessoal possível com o consumidor, priorizando a fidelização dos clientes já existentes. Estratégias publicitárias como promoções que reduzem fretes e brindes, acabam encantando o cliente, o que poderá elevar a imagem da loja no mercado B2C.

Pode-se dizer que a concorrência cresce nos diferentes tipos de mercado, na medida em que aumenta o número de consumidores de comércio eletrônico. Isso faz com que as lojas tradicionais passem a adotar uma postura mais agressiva em atrair o consumidor para continuar mantendo bom posicionamento no mercado tradicional.

Diante das análises feitas, é considerável dizer que a postura ideal de uma boa loja virtual é de ser sempre inovadora, criativa, priorizando a tecnologia em vários aspectos para operar de forma eficiente neste mercado, manter alto nível de atendimento e focar em estratégias que atraiam e fidelizem o cliente.

As principais dificuldades em assegurar uma eficiente operação logística pode decorrer no descumprimento do prazo de entrega, das más condições do produto entregue, que é originário da falta de comunicação entre empresa e prestadora de serviços, da qual pode estar desinformado sobre as condições de manuseio e entrega dos produtos que são oferecidos pelo site, o que acaba dificultando uma entrega rápida e segura ao cliente. As empresas Redemarket e Submarino que foram premiadas com ouro e diamante servem de exemplo para ás demais empresas conveniadas á e-bit que obtiveram premiação prata e bronze, a fim de que elas possam reavaliar suas estratégias, seus graus de dificuldades para posteriormente adotarem medidas semelhantes ou mais criativas do aquelas que foram expostas neste estudo. Isto têm como finalidade obter melhor posicionamento no mercado B2C e chegar á premiação ouro ou diamente pela e-bit.

\section{REFERÊNCIAS BIBLIOGRÁFICAS}

BRETZKE.Miriam. Marketing de relacionamento e competitividade em tempo real. São Paulo: Atlas, 2000. p. 72-75

BRONDMO. Hans Peter. Fidelização. São Paulo: Futura. 2001. 279 p.

E-bit.com.br. Publicação eletrônica. Disponível em:<www.ebit.com.br>. Acesso em 22 ago. 2002

FERNANDA, C. Publicação eletrônica [mensagem pessoal]. Mensagem recebida por <eapucinelli@columbia.com.br> em 23 ago. 2003.

FREDER, M. Publicação eletrônica [mensagem pessoal]. Mensagem recebida por <eapucinelli@columbia.com.br> em 27 set. 2002.

KARSAKLIAN. Eliane. Cybermarketing. São Paulo: Atlas. 2001. 155 p.

KOTLER. Philip. Administração de Marketing. 5 ed. São Paulo: Campus. 2000. p.683

MODAHL. Mary. Agora ou Nunca: como ganhar a guerra pelos consumidores na Internet. Rio de Janeiro: Campus. 2000. 238 p.

NICOLETA, Constabile. Publicação eletrônica em e-bit: Brasileiros abrem o bolso na rede. Bit notícias, fev. 2002. Disponível em:

<http://www.e-bit.com.br/ebit1/bitnoticias/htm/02fevereiro25_meiomensagem.htm.> Acesso em: 23 ago. 2002

NOVAES. Antonio Galvão. Logística e gerenciamento na cadeia de distribuição. 1 ed. Rio de Janeiro: Campus, 2001. 409 p.

Opinia.com.br. Publicação eletrônica. Disponível em: <http://www.opinia.com.br>. Acesso em 04 out. 2002 
Revista Eletrônica de Ciência Administrativa (RECADM) - ISSN 1677-7387

Faculdade Cenecista de Campo Largo - Coordenação do Curso de Administração 12 v. 2, n. 2, nov./2003 - http://revistas.facecla.com.br/index.php/recadm/

PUBLIFOLHA. Manual Prático da Internet. Agora São Paulo. São Paulo: 2002. 144.p Rede Market nos jornais: Compra pela internet conquista mais espaço. O Estado do Paraná, Paraná, 24 abr. 2001. Disponível em:

<http://www.redemarket.com.br/imprensa/impressa/estado.htm>. Acesso em 22 set. 2002

Redemarket na Imprensa. Publicação eletrônica: Redemarket.com.br. Disponível em: <http://www.redemarket.com.br/imprensa/eletronica/reportagem_globo.htm> Acesso em: 22 set. 2002

Todos os caminhos levam ao Submarino. $\mathrm{O}$ atendimento do portal. Consumidor Moderno, jul. 2001. Disponível em:

<www.padraoeditorial.localweb.com.br/c/pages/materia.asp?id=59>. Acesso em: 22 set. 2002 